\title{
Teenage Childbearing in Sweden - Depressive Symptoms among Teenage Mothers, Influencing Factors, Perception of Support and Self-Esteem - A Comparative Cross-Sectional Study
}

\section{Hertfelt Wahn Elisabeth ${ }^{1 *}$ and Nissen Eva ${ }^{2}$}

${ }^{1}$ School of Life Sciences, University of Skövde, Skövde, Sweden

${ }^{2}$ Associated Professor Department of Woman and Child Health, Division of Reproductive and Perinatal Health Care, Karolinska Institutet, Stockholm, Sweden

\begin{abstract}
Background: Becoming a teenage mother is confronted with parental responsibilities at a time when a teenage girl has to deal with her own intense development. Depressive symptoms and postpartum depression are commonly reported in teenage mothers and are of particular concern since depressive symptoms are linked with poor general health.
\end{abstract}

Objective: To examine if the perception of support, self-esteem and social background factors differ between teenage mothers with depressive symptoms compared with teenage mothers without depressive symptoms.

Design: A descriptive comparative cross-sectional study.

Participants: Swedish speaking teenage mothers aged 15-19 who gave birth in hospital in a county of south western Sweden, $n=76$. The group was divided into two groups based on their score on Edinburgh postnatal depression scale, depressive symptoms, $\mathrm{n}=24$ and without depressive symptoms, $\mathrm{n}=52$.

Measurements and

Data were collected by a questionnaire including socio-demographic variables, scales to measure support, self-esteem and depressive symptoms. Differences between teenage mothers scoring high or low on the EPDS were tested. Teenage mothers with depressive symptoms perceived less support from family and friends and had lower self-esteem than teenage mothers without depressive symptoms. They had more often been exposed to mental/physical abuse and were more often smokers than the teenage mothers without depressive symptoms. Support from the midwives were generally well perceived by teenage mothers, but support from the midwife attending delivery was less well perceived by teenage mothers with depressive symptoms.

Conclusion: Teenage mothers with depressive symptoms may have a difficult life situation characterized by low self-esteem and perceived failing support from their social network.

Implications for practice: The result suggests that assessment of the health status of the teenage mother should include screening for depressive symptoms, risk-taking behaviours and perception of current family/friend and partner support to inform individual planning of care.

Keywords: Teenage pregnancy; Health; Support; Midwife; Selfesteem; Depressive symptoms

\section{Introduction}

Becoming a teenage mother is confronted with parental responsibilities at a time when a teenage girl has to deal with her own intense development with profound physical changes, as well as cognitive, affective, moral and social development $[1,2]$. How a teenage mother responds to pregnancy is related to her early childhood experiences, coping mechanisms, personality profile, psychological function, life situation including social support network and physical status $[3,4]$. These findings illuminate that pre-childbearing characteristics can be a risk factor for adverse outcomes among certain teenage mothers $[5,6]$. One factor that has been found as having a negative effect on both mother and child is maternal depression $[7,8]$. Depressive symptoms and postpartum depression are commonly reported in teenage mothers [9] and are of particular concern since depressive symptoms are linked with poor general health [10]. There is empirical evidence showing that the prevalence of depressive symptoms is higher among teenage mothers than among older mothers [4,11]. A significant propotion of teenage pregnancies result from positive, idealised attitudes to pregnancy, parenthood and personal changes that teenagers believe will ensue. Indeed, it has been suggested that postpartum depression might be a result of disillusionment after previous idealisation of pregnancy and parenthood [12]. The complex interplay of the pre-childbearing factors makes transition into parenthood particularly challenging [13].
In this context, it is clear that teenage mothers require social support in and outside the health care system [14].

Social support aims at empowering the individual to manage her own resources to overcome various strains and difficulties [15]. It is defined as an environmental resource (emotional, material, informative and appraisal support) that is available under all or most circumstances when the need arises and is accessed and provided through reciprocal interpersonal relationships $[16,17]$. When support from a woman's network is not present, support from others - often professionals - has been related to improved health outcomes $[9,18]$.

Since support networks are actively constructed the personal characteristics of the teenage mothers are likely to play an important

*Corresponding author: Elisabeth Hertfelt Wahn, RN, RM, PhD, Senior lecturer School of Life Sciences, PO Box 408, S 54128 Skövde, Sweden, Tel: +46 500448431, E-mail: elisabeth.hertfelt.wahn@his.se

Received September 15, 2012; Accepted October 25, 2012; Published October 30, 2012

Citation: Elisabeth HW, Eva N (2012) Teenage Childbearing in Sweden Depressive Symptoms among Teenage Mothers, Influencing Factors, Perception of Support and Self-Esteem - A Comparative Cross-Sectional Study. J Nurs Care 1:123. doi:10.4172/2167-1168.1000123

Copyright: (c) 2012 Elisabeth HW, et al. This is an open-access article distributed under the terms of the Creative Commons Attribution License, which permits unrestricted use, distribution, and reproduction in any medium, provided the original author and source are credited. 
role in eliciting support from others, as well as her expectations and evaluations of the support received $[19,20]$. A factor that may affect the way a teenage mother interacts with her social network is self-esteem [21]. Self-esteem as defined by Rosenberg is a personal judgment of worthiness that is expressed in the attitudes the individual holds toward her/himself and is fostered by the family relationship [21]. Low selfesteem has been found to be a factor strongly predictive of postpartum depression [9,22-24].

In our previous study we found that Swedish speaking teenage mothers perceived less support from their social network, had lower self-esteem, and more depressive symptoms compared with older mothers in a reference group [4]. The experience of physical and psychological violence was also more common among teenage mothers than in adult mothers $[4,25]$. However, to our knowledge, prior studies have not examined if the perception of support, self-esteem and social background factors differ between teenage mothers with depressive symptoms compared with teenage mothers without depressive symptoms. Thus, the current study had the objective to examine if the perception of support, self-esteem and social background factors differed between teenage mothers 15-19 years old with depressive symptoms compared with teenage mothers 15-19 years old without depressive symptoms.

\section{Methods}

\section{Design}

This study is the second part of a descriptive comparative crosssectional study, about teenage childbearing in Sweden, which was carried out in a county in south western Sweden during a period of one year, October 2003 to October 2004 [4]. The county consists of urban, suburban and rural districts with approximately 730,000 inhabitants. During the study period all together 7811 births occurred at the delivery wards in the three hospitals in the county. During pregnancy all teenage mothers attended the antenatal clinic where they were assigned a personal midwife who supported and supervised pregnancy. Continuity of care between the antenatal clinic and the maternity clinic is generally not practiced in the study area. The investigated group of teenage mothers was selected from all three hospitals in the county with an obstetric clinic.

\section{Participants and procedure}

All Swedish speaking teenage mothers aged 15-19, giving birth in the hospitals in the county were invited to participate in the study and were asked to answer a questionnaire. The sample size was expected to be about 150 teenage mothers. This figure was based on information on pregnancy and birth statistics from the Swedish Medical Birth Registry.

Data collection by questionnaires made it necessary to exclude mothers who did not master the Swedish language. During the study period 159 teenage mothers, two percent of all births in the study area gave birth in hospital. Thirty-four teenage mothers were excluded, since they could not master the Swedish language. In all, 125 teenage mothers were eligible for the study.

The midwife assisting during labour and birth asked the participants to respond to a questionnaire while still at the maternity ward. The mothers were then asked to put the questionnaire in a return envelope and seal it. At the same time, information on their pregnancy and delivery was collected by the same midwife from their maternal health- and birth charts.

\section{Drop outs}

Twenty-eight of these teenage mothers were not contacted by the midwives in charge of data collection (the midwives did not specify the reason). The final study group comprised 97 teenage mothers. Out of the 97 teenage mothers who agreed to participate in the study, 21 declined to answer, which gave a response rate of 78 percent. A comparison between the non-responders (non approached $n=28$, drop-outs $n=21$ ) and the participants did not show any significant differences in obstetric background data, except for the number of previous pregnancies. More than half of the drop-outs $(n=10)$ and four of the non-approached group had previously been pregnant twice or more compared to five of the participants.

\section{Measures}

A questionnaire was developed which included socio-demographic variables, variables concerning health during pregnancy, support from the personal network and midwives during pregnancy and childbirth, life style, experience of physical/psychological violence, obstetric outcomes and three validated inventories (described below). Questions concerning different issues were introduced with a short text. It was possible to make additional personal comments to the questions. Obstetric background data was collected from the maternal health- and delivery charts.

\section{Pilot test}

The questionnaire was piloted on a group of 20 teenage mothers who responded to the questionnaire and gave their comments about the questions and had the possibility to express their experience about completing the questions. They affirmed that all important questions from their point of view were being asked. Some corrections were done according to their suggestions to make the questionnaire easier to answer. Three questions were added to inform of the feasibility of the questionnaire and free space was left on the last page for voluntary remarks.

\section{Inventories}

The Edinburgh Postnatal Depression Scale, EPDS [26] was used to measure maternal symptoms of depression after childbirth. The EPDS, which is one of the most widely used screening instruments for identifying depressive symptoms, is a self-report scale with ten items. Each item has four point response formats, ranging from 0 (absence of the symptom) to 3 (the symptom is very intense and present most of the time). Therefore, the EPDS total score ranges from 0 to 30 . The scale rates the intensity of depressive symptoms during the previous seven days, where a high score indicates more symptoms of depression within the previous seven days. Five of the items concern dysphoric mood, two concern anxieties, and one of each concerns guilt, coping with daily life and suicidal ideas. However, the EPDS is not a diagnostic scale for depressive disorders. To diagnose a depression a professional interview is required. The EPDS is widely used and has been validated for use post partum in several countries and demonstrates moderate to good reliability properties across samples from a wide variety of countries and languages, including Sweden [27]. Cox et al. [26] recommended different cut-offs for different purposes. Green [28] notes that the threshold is made in a pragmatic way since there is 'no true cut-off'. For the screening of women vulnerable to developing depression the threshold score of $9 / 10$ on the EPDS is recommended in primary care $[26,29,30]$. Using this cut off score, a sensitivity of $90 \%$ and a specificity of $92 \%$ has been found [27]. Further, a relationship between depressive symptoms during the first week after birth and depressive mood later 
Citation: Elisabeth HW, Eva N (2012) Teenage Childbearing in Sweden - Depressive Symptoms among Teenage Mothers, Influencing Factors, Perception of Support and Self-Esteem - A Comparative Cross-Sectional Study. J Nurs Care 1:123. doi:10.4172/2167-1168.1000123

Page 3 of 7

has been demonstrated [31]. Thus, a cut-off $9 / 10$ was used in this study for all calculations at $1-3$ days postpartum to identify teenage mothers with depressive symptoms. Teenage mothers with an EPDS score of 10 or more were in this study referred to as mothers with depressive symptoms, and teenage mothers with an EPDS score less than 10 were referred to as mothers without depressive symptoms.

Self-esteem was measured by Rosenberg's Self-Esteem Scale (SES) [21]. The scale has been widely used in varying settings and is highly recommended due to its brevity and simplicity [32]. SES [21] is a ten item self report scale with responses reported on a four point continuum from 'strongly agree' to 'strongly disagree'. The responses are clustered into six categories. Thus, some categories include more than one item. The total maximum score for the scale is six, which is also used in this study. The category responses range from $0-6$, with higher scores indicating higher self-esteem.

Maternity Social Support Scale (MSSS) was used to measure perception of received support from the social network [33]. Social factors associated with postnatal depression (lack of family support, low friendship network, lack of help from partner, conflict with partner, feeling controlled by partner, and feeling unloved by partner) are combined in a sex-item self-report, five-point Likert scale. In the present study this scale was separated between support from family/ friends and support from partner. The score on each item (ranging from 1-5) was summarized according to the origin of support. Family/friend support ranged from 1-10 and partner support ranged from 1-20. High total score indicates increased perceived support.

Based on previous work [4] a set of statements was administered to elucidate the perception of different types of support such as informative, emotional, appraisal, and instrumental support provided by the midwife. It is suggested that all acts of support can be assigned into these four attributes of support [15]. One statement addressed each of these four attributes of support received from the midwife at the antenatal clinic; at the labour ward and at the maternity ward The statements were adjusted to each environment but contained principally the same statement: 'the midwife at the antenatal clinic gave me information according to my own wishes' (informative), 'the midwife at the antenatal clinic took me seriously' (emotional) 'I felt great confidence in the antenatal midwife' (appraisal) and 'the midwife at the antenatal clinic helped me with practical things' (instrumental). The statements had a four- point response format ranging from 'do not agree at all' to 'agree completely'. In all cases 1 indicated the lowest level of support and 4 indicated the highest level of support. A mean was constructed of all the support items of different types. Thus, the maximum score on each scale is 4 .

\section{Data analysis}

To describe the material, the mean $(\mathrm{m})$ and standard deviation (SD) were used for background data on interval scale level. For study variables standard error of the mean (SEM) were given. For nominal data, absolute and relative frequencies were given. Differences between groups scoring high on the EPDS (EPDS $\geq 10$ ) or low (EPDS $<10$ ) were tested by $\chi 2$ when on nominal level and by Student's T-test for data on interval scale level. The software program used for the statistical analyses was SPSS for Windows, version 17.0 (SPSS Inc., Chicago, Illinos, USA). Additional personal comments to the questions were categorized and reported in the text.

\section{Ethical consideration}

The teenage mothers who consented to participate in the study were informed that their participation was voluntary, and that their identity was protected by confidential handling of the data. Some of the questions included in the questionnaire were of very personal character and could evoke a need for counseling. There was information in the questionnaire that a local contact person, professionally trained to meet adolescent needs, was available for the participants if needed. Permission to undertake this study was given by the Regional Ethics

\begin{tabular}{|c|c|c|c|c|c|}
\hline \multirow{2}{*}{ Variables } & \multirow{2}{*}{$\begin{array}{l}\text { EPDS }<10 \\
n=52\end{array}$} & & EPDS $\geq 10$ & & \multirow[b]{2}{*}{$\mathbf{p}$} \\
\hline & & & $n=24$ & & \\
\hline Age of teenage mother ( $\mathrm{m} \mathrm{SD}$ ) & 17.98 & 0.939 & 18.04 & 0.955 & 0.814 \\
\hline Primipara (n \%) & 51 & 98.1 & 23 & 95.8 & 0.570 \\
\hline Comfort in school $(\mathrm{n} \%)$ yes & 45 & 86.5 & 18 & 75.0 & 0.214 \\
\hline Attend school ( $m$ SD) years & 10.9 & 1.1378 & 10.5 & 1.1221 & 0.556 \\
\hline Marital status of teenage mother, cohabiting ( $\mathrm{n} \%$ ) & 43 & 82.7 & 20 & 83.3 & 0.945 \\
\hline Age of teenage mothers partner (m SD) & 22.21 & 2.783 & 22.17 & 3.595 & 0.303 \\
\hline Length of relationship with partner, month (m SD) & 27.98 & 15.903 & 27.29 & 18.229 & 0.633 \\
\hline Parents'marital status, cohabiting (n \%) & 21 & 41.2 & 5 & 21.7 & 0.105 \\
\hline Attended antenatal classes, alone ( $\mathrm{n} \%)$ & 5 & 9.8 & 5 & 20.8 & 0.190 \\
\hline Smoked during pregnancy, yes (n \%) & 14 & 31.1 & 12 & 60 & 0.028 \\
\hline Consumption of alcohol during preg. Yes ( $\mathrm{n} \%)$ & 7 & 13.7 & 5 & 20.8 & 0.433 \\
\hline Ever mentally / physically abused, yes (n \%) & 21 & 42.9 & 17 & 73.9 & 0.014 \\
\hline Complications during pregnancy, yes (n \%) & 27 & 51.9 & 15 & 62.5 & 0.389 \\
\hline Birth, gestational wks (m SD) & 38.98 & 2.322 & 39.17 & 2.078 & 0.887 \\
\hline Duration of labor, h (m SD) & 5.43 & 2.943 & 5.42 & 2.937 & 0.873 \\
\hline Mode of delivery & & & & & 0.222 \\
\hline partus normalis, yes (m SD) & 44 & 84.6 & 23 & 95.8 & \\
\hline ventouse/forceps & 6 & 11.5 & 0 & 0 & \\
\hline caesarean section & 2 & 3.8 & 1 & 4.2 & \\
\hline Birth wight, g (m SD) & 3512 & 642.80 & 3525 & 587.41 & 0.909 \\
\hline Skin to skin contact after birth, yes ( $\mathrm{n} \%$ ) & 46 & 88.5 & 22 & 91.7 & 0.672 \\
\hline First breastfeeding, within $1 \mathrm{~h}(\mathrm{n} \%)$ & 29 & 55.8 & 14 & 58.3 & \\
\hline
\end{tabular}

Table 1: Characteristics of sample 
Citation: Elisabeth HW, Eva N (2012) Teenage Childbearing in Sweden - Depressive Symptoms among Teenage Mothers, Influencing Factors, Perception of Support and Self-Esteem - A Comparative Cross-Sectional Study. J Nurs Care 1:123. doi:10.4172/2167-1168.1000123

Page 4 of 7

Committee and by each clinical Head of service for the hospitals in the county.

\section{Results}

\section{Background characteristics}

In all $24(32 \%)$ of the teenage mothers scored $\geq 10$ on the EPDS with a mean of $13 \pm 2.537$ and $52(68 \%)$ scored $<10$ on the EPDS, mean $5.42 \pm 2.562$. There were no significant differences in age, obstetric background factors such as gestational week at birth, mode of delivery, duration of labour or use of pain relief between the teenage mothers with low or high scores on the EPDS. A significantly higher proportion of teenage mothers with depressive symptoms smoked during pregnancy $(\mathrm{p}=0.028)$ and had experienced mental/physical abuse $(\mathrm{p}=0.014)$ compared to teenage mothers without depressive symptoms (Table 1 ).

Comments from both teenage mothers with and without depressive symptoms were few, but revealed that they experienced that those closest to them held a judgmental attitude towards them and their pregnancy. The teenage mothers were often exposed to comments, such as 'children should not have children'. Their community also imposed a view that they had no other identity than the identity of their partner

\section{The response pattern of EPDS}

The teenage mothers with score $\geq 10$ on the EPDS scored 3 on the items concerning guilt, anxiety and coping with daily life. Even the teenage mothers without depressive symptoms scored high on these items. The teenage mothers with depressive symptoms also scored high on two out of the five items concerning dysphoric mood (Table 2).

\section{Perception of self-esteem and social support from family/ friends and partner}

Significantly more teenage mothers with depressive symptoms (67\%) had lower self-esteem compared to teenage mothers without depressive symptoms (37\%) $(\mathrm{p}=0.014)$. Perceived mean family/friend support was significantly lower in teenage mothers with depressive symptoms when compared with teenage mothers without depressive symptoms $(\mathrm{p}=0.008)$. There was no significant difference in perceived partner support between the two groups (Table 3). Further, there were no significant differences between the two groups regarding the expected source of support. Ninety-one percent of the teenage mothers expected support from their partner. The teenage mothers also expected support from their own mother and from their partner's mother $(81 \%$ and $37 \%$, respectively).

\section{Perception of support from midwives}

Support from midwives was generally perceived to be very good, but the overall support by the midwives were perceived slightly lower by the teenage mothers with depressive symptoms, $\mathrm{p}=0.017$. When the support from midwives was further explored, it turned out that the teenage mothers with depressive symptoms perceived significantly less support from the midwives attending labour $(\mathrm{p}=0.021)$ (Table 3$)$.

Teenage mothers with depressive symptoms perceived less appraisal $(\mathrm{p}=0.023)$ and instrumental support $(\mathrm{p}=0.022)$ than mothers without depressive symptoms (Table 4).

\section{Discussion}

This study sought to examine if the perception of support, selfesteem and social background factors differed between teenage mothers with depressive symptoms compared with teenage mothers without depressive symptoms.

The main findings were that the teenage mothers with depressive symptoms, an EPDS score of 10 or more, differed according to teenage mothers without depressive symptoms, by scoring high on the dysphoric mood items of the EPDS. Teenage mothers with depressive symptoms had low self-esteem and perceived less support from family and friends. A teenage girl growing up in a family fostering a positive development in their children may also have a better self-esteem and a capacity to appreciate support while a difficult childhood and adolescence due to failing support may lead to low self-esteem and a low capacity to appreciate any support $[9,23,34]$. In this study the teenage mothers with depressive symptoms had experienced socio-psychological stressors. Being exposed to any kind of abuse was more common among teenage mothers with depressive symptoms. The depressed teenagers did also have a different lifestyle including smoking. In line with our findings other researchers show that early childhood exposure to violence predisposes adolescents to illicit drug use, teenage parenthood and depressive symptoms $[25,35]$.

Our findings support Phipps et al. [36], who identified emotional readiness for pregnancy and parenting as a significant predictor of risk factors for adverse pregnancy outcomes, such as delay of the first visit at the prenatal clinic, smoking, drinking, and depression among pregnant adolescents.

Most teenage mothers reported that they expected support from their partner and their mother. However, teenage mothers with depressive symptoms perceived less support from the family and friend network. It is possible that our findings reflect feelings of disappointment due to a discrepancy between expected support and perceived support or an ongoing conflict with the family and friend

\begin{tabular}{|c|c|c|c|c|c|c|c|c|}
\hline \multirow{2}{*}{ EPDS scores } & \multicolumn{4}{|c|}{$\mathrm{n}=52, \mathrm{EPDS}<10$} & \multirow[b]{2}{*}{0} & \multirow[b]{2}{*}{1} & \multirow[b]{2}{*}{2} & \multirow[b]{2}{*}{3} \\
\hline & & 1 & 2 & 3 & & & & \\
\hline Items & n $\quad(\%)$ & & & & n $\quad(\%)$ & & & \\
\hline I have been able to laugh and see the funny side of things & $31(60)$ & $21(40)$ & & & $7 \quad(29)$ & $10(42)$ & $7 \quad(29)$ & \\
\hline I have looked forward with enjoyment to things & $47(90)$ & $5(10)$ & & & $18(75)$ & $6(25)$ & & \\
\hline I have blamed myself unnecessarily when things went wrong & $10(19)$ & $28 \quad(54)$ & $14(27)$ & & $1 \quad(4)$ & $(8)$ & $14(58)$ & $(29)$ \\
\hline I have been anxious or worried for no good reason & $16(31)$ & $21(40)$ & $14(27)$ & $1 \quad(2)$ & $1 \quad(4)$ & $7 \quad(29)$ & $13(54)$ & $(13)$ \\
\hline I have felt scared or panicky for no very good reason & $36(69)$ & $15(29)$ & $1(2)$ & & $4(17)$ & 7 (29) & $13(54)$ & \\
\hline Things have been getting on top of me & $15(29)$ & $29(56)$ & $8(15)$ & & & $12(50)$ & $10(42)$ & $2(8)$ \\
\hline I have been so unhappy that I have had difficulty sleeping & $39(75)$ & $12(23)$ & $1(2)$ & & $3(12)$ & $10(42)$ & $11(46)$ & \\
\hline I have felt sad or miserable & $13(25)$ & $36(69)$ & $3(6)$ & & & 7 (29) & $14(58)$ & $3(13)$ \\
\hline I have been so unhappy that I have been crying & $23(44)$ & $28 \quad(54)$ & $1(2)$ & & & $15(63)$ & $8(33)$ & $1(4)$ \\
\hline The thought of harming myself has occured to me & $49 \quad(94)$ & $2(4)$ & $1(2)$ & & $17(71)$ & $6(25)$ & $1(4)$ & \\
\hline
\end{tabular}

Table 2: The response pattern of EPDS items in teenage mothers with or without depressive symptoms. 
Citation: Elisabeth HW, Eva N (2012) Teenage Childbearing in Sweden - Depressive Symptoms among Teenage Mothers, Influencing Factors, Perception of Support and Self-Esteem - A Comparative Cross-Sectional Study. J Nurs Care 1:123. doi:10.4172/2167-1168.1000123

Page 5 of 7

\begin{tabular}{|l|l|l|l|l|l|l|}
\hline & $\begin{array}{c}\text { EPDS<10 } \\
\mathbf{n = 5 2} \mathbf{~ m}\end{array}$ & $\mathbf{S E M}$ & $\begin{array}{c}\text { EPDS } \mathbf{1 0} \\
\mathbf{n = 2 4} \mathbf{m}\end{array}$ & $\mathbf{S E M}$ & $\mathbf{t}$ & $\mathbf{p}$ \\
\hline $\begin{array}{l}\text { Family and friend } \\
\text { support }\end{array}$ & 9.4038 & 0.14073 & 8.4167 & 0.31804 & 2.839 & 0.008 \\
\hline Partner support & 17.000 & 0.66080 & 16.3750 & 0.98322 & 0.530 & 0.598 \\
\hline $\begin{array}{l}\text { Support from the } \\
\text { antenatal midwife }\end{array}$ & 3.6863 & 0.08103 & 3.5313 & 0.13011 & 1.048 & 0.298 \\
\hline $\begin{array}{l}\text { Support from the } \\
\text { midwife during labor }\end{array}$ & 3.8125 & 0.05428 & 3.3993 & 0.16012 & 2.4444 & 0.021 \\
\hline $\begin{array}{l}\text { Support from the } \\
\text { maternity midwife }\end{array}$ & 3.7648 & 0.06087 & 3.5625 & 0.11485 & 1.556 & 0.128 \\
\hline $\begin{array}{l}\text { Aggregated support } \\
\text { From midwives }\end{array}$ & 3.7591 & 0.4369 & 3.4989 & 0.09408 & 2.508 & 0.017 \\
\hline
\end{tabular}

Table 3: Perceived support from family, friends, partner, antenatal midwife, midwife at the labor ward and midwife at maternity ward (mean and standard error of the mean) by teenage mothers with low or high scores on the EPDS

\begin{tabular}{|l|l|l|l|l|l|l|}
\hline & $\begin{array}{c}\text { EPDS<10 } \\
\mathbf{n = 5 2} \\
\mathbf{m}\end{array}$ & SEM & $\begin{array}{c}\text { EPDS } \geq \mathbf{1 0} \\
\mathbf{n = 2 4} \\
\mathbf{m}\end{array}$ & $\mathbf{~ S E M ~}$ & $\mathbf{t}$ & $\mathbf{p}$ \\
\hline Informative support & 3.6293 & 0.06686 & 3.3056 & 0.15004 & 1.971 & 0.057 \\
\hline Appraisal support & 3.8399 & 0.03932 & 3.6806 & 0.08389 & 1.966 & 0.053 \\
\hline Emotional support & 3.7700 & 0.05236 & 3.5556 & 0.07684 & 2.320 & 0.023 \\
\hline Instrumental support & 3.7971 & 0.04994 & 3.4603 & 0.12905 & 2.434 & 0.022 \\
\hline
\end{tabular}

Table 4: Different forms of midwifery support perceived by the teenage mothers with low or high scores on the EPDS. Lower scores indicate lower satisfaction with the support provided.

network [23]. Although the teenage mothers often have conflict with their parents they still value them as an important source of support [14].

There was no significant difference between teenage mothers with or without depressive symptoms in the perception of partner support and the relationship with the partner had lasted for average two years in both groups. Thus, the relationship with the partner seemed stable, which may compensate for the discrepancy between the expected and actually perceived support from the family and friend network. The finding that teenage mothers with depressive symptoms also showed low self-esteem is likely to play an important role in eliciting support from others, as well as evaluating the support received [19]. Furthermore, both low self-esteem and depressive symptoms may lead to difficulties in functioning in the maternal role and developing a positive maternal self-esteem [37]. Mercer [38] reports that maternal self-esteem develops within the intimate relationship between a mother and her new baby and is a value a woman places on herself as a mother. Positive maternal self-esteem enriches a woman's capacity to achieve a maternal identity and helps her identify the cues of her baby [38]. Since self-esteem is shown to be associated with parenting skills, it would seem appropriate that midwives are aware of this phenomenon in their encounter with the teenage mothers, since good self-esteem promotes the competence to adequately nurture the emotional development of the next generation [39].

Support from midwives was generally well perceived. There was no difference between teenage mothers with or without depressive symptoms in the perception of support from the antenatal and the maternity midwife. However, teenage mothers with depressive symptoms perceived significantly less support from the midwife attending labour. It is unclear why the teenage mothers with depressive symptoms reported this. To come to a maternity hospital to give birth in a novel environment, breaks the continuity of care which has been established at the antenatal clinic, leaving the vulnerable teenager in a vacuum while finding a new reliable safe support. The delivery ward midwife has the difficult task to establish a new safe base for the teenager during a very intensive and short period $[40,41]$. The vulnerable teenage mother highlights the importance of continuity of care. From a previous study we learned that a sense of trust for the midwife can be developed when the teenage mother is taken seriously. Trust makes the teenage mother willing to express how she feels [42] and what she needs which is necessary during the intense period of labour and birth [43].

Both teenage mothers with and without depressive symptoms noted negative attitudes among those closest to them. Especially the attitude that the teenage mother got her identity only through her partner was insulting them. This result is in line with an earlier study by Wahn [3] where the teenage mothers reported that they had experienced negative public attitudes towards them, which they were unprepared to meet. It is important that the midwife and other health care providers really takes the teenage mothers seriously and try to understand their individual needs [42].

The findings in this study should be considered in relation to its limitations including a small sample size and methodological issues with the measurement of depressive symptoms and maternal social support. Because of the small sample size the statistical analysis and the comparison between groups were limited. If the teenage mothers, who were excluded due to language difficulties, also had been included the results might have been different. Future research should therefore include larger samples from multiple sites with an ethnic diversity that represents the population of Sweden and using a variety of alternative methods. This may help to improve the generalization of the findings.

MSSS and EPDS were developed for pregnant woman and have been used in other samples of teenage mothers $[33,44,45]$ and were therefore chosen for this study. MSSS was developed to meet the need for a brief tool of measuring perceptions of adequacy of social support among pregnant women. The EPDS was specifically designed to screen for postnatal depression in community samples and has also been used at week 1 postpartum with good predictive power [31]. The baby blues usually emerge four-five days post-partum and has disappeared by day seven to ten [46]. To answer the questionnaire day 1-3 after child birth may reduce the risk of reflecting the post-partum blues in the answers to the EPDS, but still the results need to be interpreted with caution. Henshaw [46] review of screening instruments for postpartum depression showed that the EPDS purposefully excludes somatic symptoms of depression but is highly correlated with anxiety measures, suggesting that symptoms related to caretaking of a new infant may be a part of post-partum depression. As shown in Table 2 the teenage mothers with depressive symptoms scored particularly high on the anxiety items. The study design included both background factors and SES [47]. This design underpins the interpretation that the teenage mothers scoring high on EPDS really are at risk of developing depression.

Further development and validation of the instrument "support from midwives" is needed, especially to elucidate what is lacking in the midwives' instrumental and appraisal support to better capture the needs of the teenage mother. Also further intervention studies are needed to meet the teenage mother in a way that will help her managing her developmental tasks both to become an adult and to become a mother at the same time, such as self-help groups and continuity of care. 
Citation: Elisabeth HW, Eva N (2012) Teenage Childbearing in Sweden - Depressive Symptoms among Teenage Mothers, Influencing Factors, Perception of Support and Self-Esteem - A Comparative Cross-Sectional Study. J Nurs Care 1:123. doi:10.4172/2167-1168.1000123

Page 6 of 7

\section{Conclusion}

The study showed that teenage mothers with depressive symptoms as measured by EPDS with a cut-off point $9 / 10$ perceived less support from family and friends and had lower self-esteem than teenage mothers without depressive symptoms. They had more often been exposed to abuse and were more often smokers than the teenage mothers without depressive symptoms. Support from the midwives were generally well perceived by teenage mothers, but support from the midwife attending delivery was less well perceived by teenage mothers with depressive symptoms.

\section{Clinical Implications}

The study results hold implications for midwives and other health care providers. The results suggest that assessment of the health status of the teenage mother should include screening for depressive symptoms with a focus on the dysphoric mood items, risk taking behaviours and her perception of current family/friend and partner support, and emotional readiness for pregnancy as a basis for further planning of care and support.

\section{Acknowledgment}

The study was supported by grants from the Skaraborg Institute for Research and Development and the School of Life Sciences, University of Skövde, Sweden.

\section{References}

1. Raphael-Leff J (1991) Psychological processes of childbearing. Chapman and Hall, London.

2. Coleman JC (1999) The nature of adolescence. (3rd edn), Routledge, London.

3. Wahn EH, Nissen E, Ahlberg BM (2005) Becoming and being a teenage mother: how teenage girls in South Western Sweden view their situation. Health Care Women Int 26: 591-603.

4. Wahn EH, Nissen E (2008) Sociodemographic background, lifestyle and psychosocial conditions of Swedish teenage mothers and their perception of health and social support during pregnancy and childbirth. Scand J Public Health 36: 415-423.

5. Pawlby S, Hay D, Sharp D, Waters CS, Pariante CM (2011)Antenatal depression and offspring psychopathology: the influence of childhood maltreatment. $\mathrm{Br} J$ Psychiatry 199: 106-112.

6. Ramos-Marcuse F, Oberlander SE, Papas MA, McNary SW, Hurley KM, et al (2010) Stability of maternal depressive symptoms among urban, low-income, African American adolescent mothers. J Affect Disord 122: 68-75.

7. Josefsson A, Berg G, Nordin C, Sydsjö G (2001) Prevalence of depressive symptoms in late pregnancy and postpartum. Acta Obstet Gynecol Scand 80: 251-255

8. Rubertsson C, Wickberg B, Gustavsson P, Rådestad I (2005) Depressive symptoms in early pregnancy, two months and one year postpartum-prevalence and psychosocial risk factors in a national Swedish sample. Arch Womens Ment Health 8: 97-104.

9. Logsdon MC, Cross R, Williams B, Simpson T (2004) Prediction of postpartum social support and symptoms of depression in pregnant adolescents: a pilot study. J Sch Nurs 20: 36-42.

10. Saluja G, lachan R, Scheidt PC, Overpeck MD, Sun W, et al. (2004) Prevalence of and risk factors for depressive symptoms among young adolescents. Arch Pediatr Adolesc Med 158: 760-765.

11. Figueiredo B, Pacheco A, Costa R (2007) Depression during pregnancy and the postpartum period in adolescent and adult Portuguese mothers. Arch Womens Ment Health 10: 103-109.

12. Condon JT, Donovan J, Corkindale CJ (2001) Australian adolescents' attitudes and beliefs concerning pregnancy, childbirth and parenthood: the development, psychometric testing and results of a new scale. J Adolesc 24: 729-742.

13. Szigethy EM, Ruiz P (2001) Depression among pregnant adolescents: an integrated treatment approach. Am J Psychiatry 158: 22-27.
14. Bunting L, McAuley C (2004) Teenage pregnancy and motherhood: the contribution of support. Child and Family Social Work 9: 207-215.

15. Oakley A (1988) Giving support in pregnancy: The role of research midwives in a randomized controlled trail. In: Robinson S, Thomson A (Eds) Midwives, research and childbirth. Chapman and Hall, London.

16. Sarason BR, Pierce G, Sarason IG (1990) Social support: the sense of acceptance and the role of relationships. In: Sarason BR, Sarason IG, Pierce G (Eds) Social support: an interactional view. J Wiley \& Sons, New York.

17. Maton KI, Teti DM, Corns KM, Vieira-Baker CC, Lavine JR, et al. (1996) Cultural specificity of support sources, correlates and contexts: three studies of AfricanAmerican and caucasian youth. Am J Community Psychol 24: 551-587.

18. Ekström A, Guttke K, Lenz M, Hertfelt Wahn E (2011) Long term effects of professional breastfeeding support - An intervention. Int J Nurs Mid 3: 109-117.

19. Stevenson W, Maton KI, Teti DM (1999) Social support, relationship quality, and well-being among pregnant adolescents. J Adolesc 22: 109-121.

20. Quinlivan JA, Luehr B, Evans SF (2004) Teenage mother's predictions of their support levels before and actual support levels after having a child. J Pediatr Adolesc Gynecol 17: 273-278.

21. Rosenberg M (1972) Society and the adolescent self-image. Princeton University Press, Princeton.

22. Wang SY, Chen CH, Chin CC, Lee SL (2005) Impact of postpartum depression on the mother-infant couple. Birth 32: 39-44

23. Reid V, Meadows-Oliver M (2007) Postpartum depression in adolescent mothers: an integrative review of the literature. J Pediatr Health Care 21: 289298.

24. Emmanuel E, St John W (2010) Maternal distress: a concept analysis. J Adv Nurs 66: 2104-2115.

25. Logsdon MC, Ziegler C, Hertweck P, Pinto-Foltz M (2008) Testing bioecological model to examine social support in postpartum adolescents. $J$ Nurs Scholarsh 40: 116-123.

26. Cox JL, Holden JM, Sagovsky R (1987) Detection of postnatal depression. Development of the 10-item Edinburgh Postnatal Depression Scale. $\mathrm{Br} J$ Psychiatry 150: 782-786.

27. Lundh W, Gyllang C (1993) Use of the Edinburgh Postnatal Depr0065ssion Scale in some Swedish child health care centres. Scand J Caring Sci 7: 149154

28. Green JM (1998) Postnatal depression or perinatal dysphoria? Findings from a longitudinal community-based study using the Edinburgh Postnatal Depression Scale. J Reprod Infant Psychol 16: 143-155

29. Eberhard-Gran M, Eskild A, Tambs K, Samuelsen SO, Opjordsmoen S (2002) Depression in postpartum and non-postpartum women: prevalence and risk factors. Acta Psychiatr Scand 106: 426-433.

30. Seimyr L, Edhborg M, Lundh W, Sjögren B (2004) In the shadow of maternal depressed mood: experiences of parenthood during the first year after childbirth. J Psychosom Obstet Gynaecol 25: 23-34.

31. Dennis CL (2004) Can we identify mothers at risk for postpartum depression in the immediate postpartum period using the Edinburgh Postnatal Depression Scale? J Affect Disord 78: 163-169.

32. Bowling A (2001) Measuring health: A review of quality of life measurement scales. (3rdedn), Open university Press, Buckingham.

33. Webster J, Linnane JW, Dibley LM, Hinson JK, Starrenburg SE, et al. (2000) Measuring social support in pregnancy: can it be simple and meaningful? Birth 27: 97-101.

34. Quinlivan JA, Tan LH, Steele A, Black K (2004) Impact of demographic factors, early family relationships and depressive symptomatology in teenage pregnancy. Aust N Z J Psychiatry 38: 197-203.

35. Gavin AR, Lindhorst T, Lohr MJ (2011) The prevalence and correlates of depressive symptoms among adolescent mothers: results from a 17-year longitudinal study. Women Health 51: 525-545.

36. Phipps MG, Nunes AP (2011) Assessing Pregnancy Intention and Associated Risks in Pregnant Adolescents. Matern Child Health J.

37. Secco ML, Profit S, Kennedy E, Walsh A, Letourneau N, et al. (2007) Factors affecting postpartum depressive symptoms of adolescent mothers. J Obstet Gynecol Neonatal Nurs 36: 47-54. 
Citation: Elisabeth HW, Eva N (2012) Teenage Childbearing in Sweden - Depressive Symptoms among Teenage Mothers, Influencing Factors, Perception of Support and Self-Esteem - A Comparative Cross-Sectional Study. J Nurs Care 1:123. doi:10.4172/2167-1168.1000123

38. Mercer R (1995) Becoming a mother: Research on maternal identity from Rubin to the present (2ndedn), Springer Pub Co, New York.

39. Erikson EH (1965) Barnet och samhället (2ndedn), Natur \& Kultur, Stockholm.

40. Harris M, Garris C (2008) You never get a second chance to make a first impression: Behavioral consequences of first impressions. In: Ambady $\mathrm{N}$, Skowronski J (Eds.), First impressions. Guilford Publications, New York.

41. Berg M, Asta Ólafsdóttir O, Lundgren I (2012) A midwifery model of womancentred childbirth care--in Swedish and Icelandic settings. Sex Reprod Healthc 3: $79-87$

42. Hertfelt Wahn E, von Post I, Nissen E (2007)A description of Swedish midwives' reflections on their experience of caring for teenage girls during pregnancy and childbirth. Midwifery 23: 269-278.
43. Sleutel MR (2003) Intrapartum nursing: integrating Rubin's framework with social support theory. J Obstet Gynecol Neonatal Nurs 32: 76-82.

44. Gaff-Smith M (2003) The relationship between self-esteem, social support and postnatal depression in adolescent mothers in rural South Wales. Birth Issues 12: $69-75$.

45. Figueiredo B, Bifulco A, Pacheco A, Costa R, Magarinho R (2006) Teenage pregnancy, attachment style, and depression: a comparison of teenage and adult pregnant women in a Portuguese series. Attach Hum Dev 8: 123-138.

46. Henshaw C (2003) Mood disturbance in the early puerperium: a review. Arch Womens Ment Health 6: S33-42.

47. Boyd RC, Le HN, Somberg R (2005) Review of screening instruments for postpartum depression. Arch Womens Ment Health 8: 141-153. 